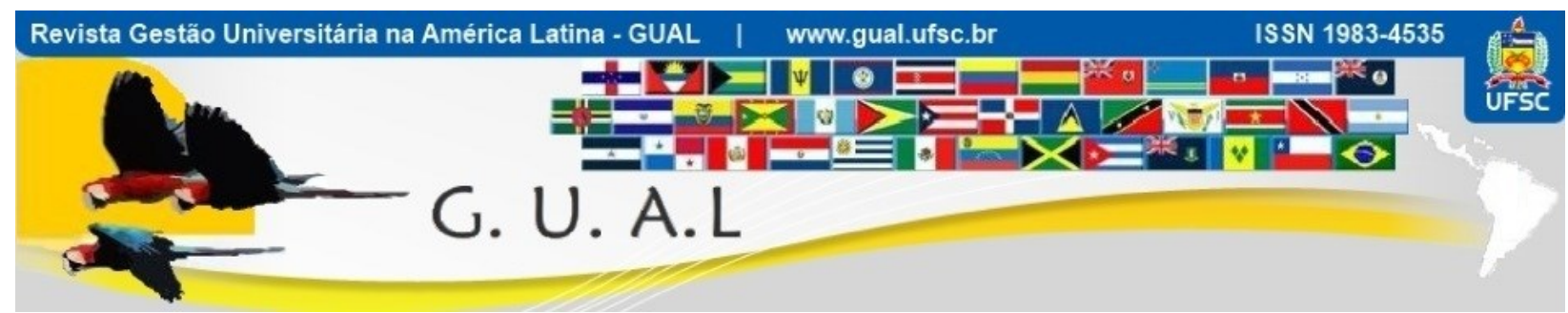

DOI: http://dx.doi.org/10.5007/1983-4535.2017v10n3p121

\title{
EXTENSÃO EM ADMINISTRAÇÃO NA UNIOESTE, CAMPUS FRANCISCO BELTRÃO: ALINHAMENTO OU FRAGMENTAÇÃO NA FORMAÇÃO?
}

\author{
EXTENSION IN BUSINESS ADMINISTRATION IN UNIOESTE CAMPUS \\ FRANCISCO BELTRAO: ALIGNMENT OR FRAGMENTATION IN TRAINING?
}

Gilberto Francisco Ceretta, Doutor Universidade Positivo - UP gilbertoceretta@gmail.com

Rosane Calgaro, Doutora Universidade Positivo - UP rocalgaro@yahoo.com.br

João Carlos da Cunha, Doutor Universidade Positivo - UP jccunhaisat@gmail.com

Recebido em 30/dezembro/2015

Aprovado em 23/junho/2017

Sistema de Avaliação: Double Blind Review

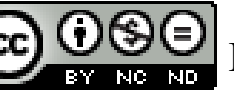

Esta obra está sob uma Licença Creative Commons Atribuição-Uso. 


\title{
RESUMO
}

A extensão constitui um dos elementos do tripé considerado fundamental na formação superior aliada ao ensino e à pesquisa. $\mathrm{O}$ objetivo deste artigo foi uma análise das práticas de extensão da Universidade Estadual do Oeste do Paraná - Unioeste, com foco nos projetos desenvolvidos no Curso de Administração do campus de Francisco Beltrão. A pesquisa se caracterizou como qualitativa, sendo os dados primários obtidos através de entrevistas com coordenadores dos projetos em atividade, caracterizando-se como um estudo de corte transversal. Os dados foram analisados através da análise de conteúdo. A apresentação da estrutura voltada à extensão se deu através da consulta a documentos do Conselho de Pesquisa e Ensino e Extensão (CEPE) e resoluções que regulamentam tais atividades. Complementam os dados secundários do estudo os projetos das atividades em vigência no curso de administração no campus Francisco Beltrão. Os resultados, sob um primeiro olhar, apontam alinhamento das práticas extensionistas da Unioeste, de forma ampla, e, especificamente, do Curso de Administração do campus Francisco Beltrão. Entretanto, em uma perspectiva crítica, o estudo revela ausência de articulação da extensão com o ensino e a pesquisa, corroborando com a fragmentação na formação superior em administração.

Palavras chave: Prática extensionista. Curso de Administração. Tripé universitário.

\begin{abstract}
The extension is one of the tripod elements considered essential in higher education coupled with teaching and research. This paper was an analysis of the State University extension practices the West of Paraná - Unioeste, focusing on projects developed on campus Administration Course Francisco Beltrao. The research is characterized as qualitative, with primary data obtained through interviews with coordinators of the project activity, characterized as a cross-sectional study. Data were analyzed using content analysis. The presentation of the structure facing the extension was given by consulting the documents of the Council for Research and Education and Extension (ECE) and resolutions regulating such activities. Complement secondary data from the study projects the activities in force in the management course on campus Francisco Beltrao. The results under a first look, point alignment of extension practices Unioeste, broadly, and specifically the campus Administration Course Francisco Beltrao. However, from a critical perspective, the study reveals no extension of articulation with teaching and research, supporting the fragmentation in the education of administration.
\end{abstract}

Keywords: Extension practice. Administration Course. University tripod. 


\section{INTRODUÇÃO}

Pensar a razão de ser da universidade vai além da visão de senso comum defensora da formação voltada ao mercado de trabalho. Implícitas na atuação universitária estão ações de produção do conhecimento, formação profissional e inserção na comunidade. Nesse sentido as atividades de extensão começam a fortalecer uma trajetória sem volta estando presentes em diversos cursos, mesmo aqueles sem uma tradição nesta prática.

A extensão constitui um dos elementos do tripé considerado fundamental na formação superior aliada ao ensino e à pesquisa. A experiência brasileira em atividade extensionista, embora seja recente (a partir da década de 1970), revela uma trajetória com início voltado à uma visão assistencialista. Mudanças na perspectiva de educação resultaram em alterações na concepção da extensão, da visão assistencial à uma atividade promotora de saberes, se articulada diretamente aos demais elementos da tríade (ensino e pesquisa). Entretanto, a consulta na realidade, em termos de eventos, publicações e até incentivos financeiros, revela a extensão com menor visibilidade em relação ao ensino e à pesquisa.

Este trabalho constitui uma análise das práticas de extensão da Universidade Estadual do Oeste do Paraná - Unioeste, com foco nos projetos desenvolvidos no curso de administração do campus de Francisco Beltrão. Após uma breve conceituação do tema são apresentados os procedimentos metodológicos usados na análise, estes são seguidos da exposição ampla das ações da Unioeste e do curso em foco. Por fim, apresenta-se a análise das ações descritas seguida das considerações finais.

\section{A EXTENSÃO NA UNIVERSIDADE}

Carbonari e Pereira (2007) relatam como iniciativas de extensão universitária no Brasil envolvendo algumas conferências e semanas abertas ao público em geral no período 1911-1917. Estas atividades não abordavam temáticas sociais, políticas e econômicas da sociedade da época. Algumas mudanças neste sentido vão aparecer na descrição feita por Rocha (2001) que aponta como relevante na implantação oficial das atividades de extensão no Brasil o processo de reforma universitária na década de 1930. A partir do movimento da Escola Nova, que passa a ocupar espaços de destaque no governo, com a elaboração do Decreto 19.851 de 11 de abril de 1931. Tal documento define extensão como "cursos de extensão universitária, destinados a prolongar, em benefício coletivo, a atividade técnica e cientifica dos institutos universitários” (ART. 35, DECRETO nº 19.851/1931). 
A lei determinava a efetivação da extensão por meio de cursos e conferências de caráter educacional ou utilitário, uns e outros organizados pelos diversos institutos da universidade, com prévia autorização do Conselho Universitário (art. 42). Ainda no mesmo artigo, a lei apresentava os destinatários e os meios pelos quais seriam efetivadas as atividades de extensão:

$[\ldots]$

$\S 1^{\circ}$ Os cursos e conferências, de que trata este artigo, destinam-se principalmente à difusão de conhecimentos úteis à vida individual ou coletiva, à solução de problemas sociais ou à propagação de ideias e princípios que salvaguardem os altos interesses nacionais.

$\S 2^{\circ}$ Estes cursos e conferências poderão ser realizados por qualquer instituto universitário em outros institutos de ensino técnico ou superior, de ensino secundário ou primário ou em condições que os façam acessíveis ao grande público

(ART. 42, PARÁGRAFOS $1^{\circ}$ e $2^{\circ}$ do DECRETO n $19.851 / 1931$ )

Pelo decreto $n^{\circ} 19.851$ de 11/04/1931, aborda-se uma breve conceituação e algumas formas de realização de extensão universitária, conforme o artigo 109.

[...] A extensão universitária destina-se à difusão de conhecimentos, filosóficos, artísticos, literários e científicos, em benefício do aperfeiçoamento individual e coletivo.

$\S 1^{\circ}$ De acordo com os fins acima referidos, a extensão universitária será realizada por meio de cursos intra e extra-universitários, de conferências de propaganda e ainda de demonstrações práticas que se façam indicadas. (ART. 109 e PARÁGRAFO $1^{\circ}$ do DECRETO nº 19.851/1931)

Correa (2003, p. 13) discute o conceito de extensão universitária a partir da definição proposta pelo Plano Nacional de Extensão como “o processo educativo, cultural e científico que articula o ensino e a pesquisa de forma indissociável e viabiliza a relação transformadora entre a universidade e a sociedade". Assim a extensão é vista como parte da missão social da universidade constituindo um caminho para superar a visão elitista e hegemônica da universidade. Tal visão conduz à necessidade de superação de algumas definições consideradas errôneas da atividade de extensão, entre elas a que identifica a extensão como um simples repasse de conhecimento à sociedade. Outra definição a ser suplantada é a que entende extensão como prática social da universidade direcionada às áreas marginais da sociedade.

A visão acima apresentada resulta do entendimento das lideranças de extensão das universidades públicas brasileiras (Fórum nacional dos pró-reitores das universidades públicas 
brasileiras) que, a partir dele, apresentam algumas diretrizes caracterizadoras da extensão. Trata-se de contemplar de forma associada perspectivas orientadas à: (i) relação social de impacto; (ii) bilateralidade; (iii) interdisciplinaridade e indissociabilidade do ensino, da pesquisa e da extensão.

Ainda na definição da extensão, o plano nacional esclarece que se trata de uma via de mão dupla que possibilita à comunidade acadêmica, em contato com a sociedade, a construção do conhecimento. Implícita nesta dinâmica encontra-se uma reflexão sobre a teoria que é acrescentada ao conhecimento. Tal dinâmica permite a troca de saberes acadêmicos e populares e, ao mesmo tempo, um processo de democratização do saber acadêmico com participação da comunidade (FORPROEX, 2007).

Neste contexto o plano Nacional de extensão tem entre seus objetivos a concretização da extensão em função das necessidades reais da sociedade e indispensável à formação dos acadêmicos, a garantia da bidirecionalidade entre universidade e sociedade em função de prioridade focada em problemas sociais. Também estão contemplados nos objetivos os aspectos de: (i) multi, inter e transdisciplinaridade envolvendo diferentes profissionais; (ii) o uso da tecnologia como meio para qualificação da educação; (iii) a preservação cultural e artística para afirmar a identidade nacional e regional; (iv) a inserção de educação ambiental e sustentabilidade e; (v) interinstitucionalização de programas extensionistas por meio de consórcios, redes e parcerias. O plano prevê a adoção da avaliação institucional da extensão e vislumbra a possibilidade de novas formas de produção do conhecimento que conduzam a ampliação do acesso ao saber e desenvolvimento da tecnologia no país (FORPROEX, 2007).

De acordo com Serrano (2008) numa análise histórica da extensão universitária no Brasil, pode-se perceber quatro momentos relevantes de sua conceituação e prática: $1^{\circ}$ ) o modelo da transmissão vertical do conhecimento; $2^{\circ}$ ) o voluntarismo e a ação voluntaria sócio-comunitária; $3^{\circ}$ ) a ação sócio-comunitária institucional e; $4^{\circ}$ ) o acadêmico institucional. Esses momentos fazem parte da transitoriedade de cada universidade em sua história e projetos pedagógicos, sendo assim, pode-se encontrar instituições em diferentes estágios.

Em uma perspectiva crítica que defende a formação emancipadora do ser humano, a extensão vai além da simples transmissão ou comunicação de conhecimento e técnicas científicas. Tem um sentido do agente da extensão (extensionista) "educar e educar-se" (FREIRE, 1977, p.25), significa levar o conhecimento produzido na universidade até a comunidade sem desconsiderar o saber implícito nas suas práticas, que também é 
conhecimento. Este conhecimento histórico e contextualmente formado que pauta as ações rotineiras da comunidade também educa o extensionista. Já a comunidade que recebe a extensão, tende a perfeiçoar suas práticas a partir da apreensão do conhecimento acadêmico transformando seu pensar e fazer.

Uma experiência da extensão articulada aos demais elementos da tríade é descrita Sousa e Silva (2008) no programa "Atividade Curricular em Comunidade" (ACC) da UFBA . Neste caso predomina a visão da extensão como responsável pelo compromisso social da universidade e ação concreta da relação universidade e sociedade. O trabalho recupera a orientação da Lei de Diretrizes e Bases da Educação sobre o papel da extensão como fortalecedora da articulação teórico-prática na estrutura curricular da formação superior.

A ACC pode articular novos modelos de organização dos currículos auxiliando as disciplinas existentes, reduzindo a fragmentação do conhecimento, dando novo significado às aulas e aproximando a formação à temáticas das demandas sociais. Na prática extensionista, o aluno envolvido em situações reais, é motivado à problematização e questionamento frente à realidade social e tende a estar engajado no concreto do cotidiano onde está inserido (SOUZA; SILVA, 2008).

\subsection{EXTENSÃO NA FORMAÇÃO EM ADMINISTRAÇÃO}

Tratando-se de uma subárea da grande área do conhecimento voltada à ciências sociais aplicadas, também na administração a extensão encontra-se em posição considerada inferior à pesquisa e ao ensino. Enquanto o ensino no Brasil se inicia na década de 1940 (BERTERO, 2006), a extensão formalmente se torna presente somente no artigo $8^{\circ}$ das diretrizes nacionais da graduação conforme a Resolução $n^{0} 4$ de 13/06/2005 emitida pelo Conselho Nacional de Educação/Câmara de Educação Superior.

Art. $8^{\circ}$ As Atividades Complementares são componentes curriculares que possibilitam o reconhecimento, por avaliação, de habilidades, conhecimentos e competências do aluno, inclusive adquiridas fora do ambiente escolar, incluindo a prática de estudos e atividades independentes, transversais, opcionais, de interdisciplinaridade, especialmente nas relações com o mundo do trabalho e com as ações de extensão junto à comunidade. (MEC Resolução $n^{\circ}$ 4, de 13/07/2005)

Se, por um lado o documento limita a extensão apenas como possibilidade de atividade complementar não tendo o mesmo destaque atribuído a pesquisa, de outro lado explicita uma ampliação para além do foco nos negócios, característico da administração, ao 
fazer referência à interdisciplinaridade e ao mundo do trabalho. Dado que os projetos pedagógicos dos cursos seguem tais diretrizes, a condição atribuída à extensão explica o número reduzido de atividades de extensão em relação as outras atividades componentes do tripé da formação superior. Na administração a discussão sobre extensão é mais recente e está implícita nas atividades voltadas à gestão e desenvolvimento do setor produtivo, estando também inclusos os cursos pagos (CORRÊA, 2003).

A análise do desempenho da UFSC em atividades extensionistas no período 19972003 revelou uma participação de 5,17\% do centro sócio-econômico (CSE), onde estão lotados os departamentos das ciências sociais aplicadas, no total das ações realizadas na universidade. O departamento de ciência da administração realizou $60 \%$ das ações desenvolvidas pelo CSE, destacam-se atividades em maior número viagens de estudo, cursos, assessorias e palestras (VARGAS, FELIX \& MATOS, 2004).

\section{PROCEDIMENTOS METODOLÓGICOS}

Trata-se de pesquisa de natureza qualitativa com base em dados primários e secundários e prioriza a busca de informações qualitativas a respeito do fenômeno investigado (LAKATOS \& MARCONI, 2010). A pesquisa envolveu um breve relato de forma ampla da extensão e sua localização na estrutura institucional da universidade e, mais especificamente, a descrição e análise das atividades extensionistas desenvolvidas no curso de administração no campus Francisco Beltrão.

A apresentação da estrutura voltada à extensão se deu através da consulta à documentos do Conselho de Pesquisa e Ensino e Extensão (CEPE) e resoluções que regulamentam tais atividades. Complementam os dados secundários do estudo os projetos das atividades em vigência no curso de administração no campus Francisco Beltrão. Os dados primários foram obtidos através de entrevistas com coordenadores dos projetos em atividade, sendo caracterizado como um estudo de corte transversal. Os dados foram analisados através da análise de conteúdo com transcrição de partes dos discursos dos coordenadores dos projetos que destacam a visão dos mesmos acerca do papel da extensão na formação em administração.

\section{APRESENTAÇÃO E ANÁLISE DOS DADOS}


Inserida na estrutura da Universidade Estadual do Oeste do Paraná, a Pró-reitoria de Extensão (PROEX) é responsável por planejar, coordenar, acompanhar e avaliar todas as atividades referentes à extensão universitária. Essas atribuições, associadas às discussões a nível nacional e regional, com respaldo dos Campi da instituição em estudo, estão propostas no Plano Institucional de Extensão da Unioeste. A partir do conteúdo do plano nacional e das discussões com a comunidade acadêmica, são definidas as diretrizes norteadoras da extensão da universidade (CEPE, 2002).

As diretrizes para extensão na Unioeste partem do entendimento de que houve uma passagem de uma visão assistencialista à uma concepção da extensão como articuladora da pesquisa e do ensino também produtora de conhecimento. Nesta perspectiva a extensão viabiliza a troca de saberes sistematizados, acadêmico e popular, conduzindo à democratização do conhecimento, com efetiva participação da comunidade na atuação universitária. Também decorrentes do plano em nível nacional, a Unioeste adota política de extensão buscando atender as áreas temáticas de comunicação, cultura, direitos humanos, educação, saúde, meio ambiente, tecnologia e trabalho (CEPE, 2002)

De acordo com o boletim de dados, expresso pela pró-reitoria de planejamento, houve um crescimento nas atividades de extensão no período de 2008-2012, conforme observado na figura 1 .

Figura 1 Comparativo de evolução quantitativa das atividades de extensão no período 2008-2012

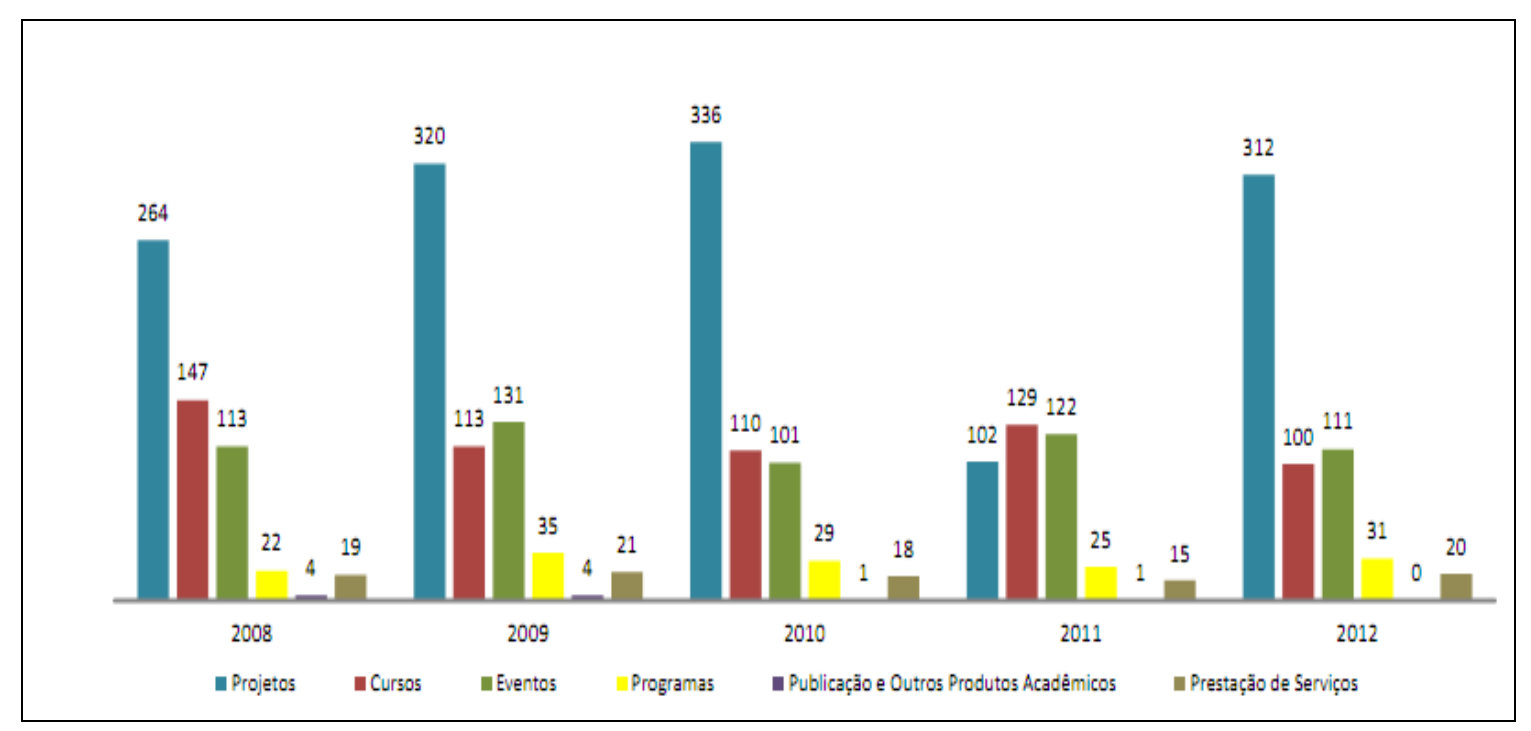

Fonte: Proplan - Unioeste (2013) 
Segundo a resolução no 363/2007 - CEPE UNIOESTE, o conceito de cada uma das atividades de extensão pode ser expresso da seguinte forma:

Art. $4^{\circ}$ Programa é conjunto articulado de, no mínimo, três (3) ações com objetivos comuns e clareza de diretrizes, preferencialmente integrando as ações de extensão, de pesquisa e de ensino, [...].

Art. $5^{\circ}$ Projeto é uma ação processual e contínua de caráter educativo, social, cultural, científico e/ou tecnológico, com objetivos específicos.

Art. $6^{\circ}[\ldots]$ Curso uma ação pedagógica, de caráter teórico e/ou prático, presencial e/ou a distância, planejada e organizada de modo sistemático, com carga horária total de no mínimo 8 (oito) horas e critérios de avaliação definidos.

Art. $7^{\circ}$ Evento é uma ação que implica na apresentação e/ou exibição pública, livre ou com clientela específica, do conhecimento ou produto cultural, artístico, esportivo, científico e tecnológico, desenvolvido, conservado ou reconhecido pela Universidade, [...]

Art. $8^{\circ}$ Prestação de Serviço é uma ação extensionista, contratada por terceiros, que se define como a execução ou participação em atividades profissionais, a partir dos conhecimentos ou habilidades de domínio da Universidade ou de seus profissionais.

$\mathrm{Na}$ figura 1, percebe-se que os projetos de extensão e cursos são os mais desenvolvidos pela comunidade acadêmica na instituição, tendo os eventos um número expressivo.

Quanto a bolsas específicas para atividades de extensão, a Unioeste aprovou a Resolução no 318/2005 CEPE, anos mais tarde revogada pela Resolução no 102/2009 - CEPE, instituindo assim a regulamentação na distribuição de bolsas, como explicita o artigo $1^{\mathrm{o}}$ :

Art. $1^{\circ}$ O Programa Institucional de Bolsas de Extensão, tem por finalidade viabilizar a participação de alunos regularmente matriculados em curso de graduação da UNIOESTE, num processo de interação entre a Universidade e a Sociedade, por meio de trabalhos sistemáticos (consoante com sua área de formação) que contribuam para a formação acadêmica, profissional, o exercício da cidadania e o fortalecimento da responsabilidade social dos universitários. (ANEXO I - RESOLUÇÃO no 102/2009 - CEPE)

Já os critérios de concessão das bolsas institucionais estão firmadas no artigo $5^{\circ}$, da seguinte forma:

Art. $5^{\circ}$ As bolsas são vinculadas somente à Atividade de Extensão caracterizada como Programa ou Projeto, ficando estabelecidos os seguintes critérios para participação do processo de seleção:

I. - estar aprovada e cadastrada no Banco de Dados da Pró-Reitoria de Extensão;

II. - estar regularizada conforme a Resolução especifica que estabelece 
normas e procedimentos para Atividades de Extensão;

III. - ter caráter multidisciplinar ou interdisciplinar ou unidisciplinar;

IV. - articular o Ensino e a Pesquisa no seu desenvolvimento;

V- ter envolvimento prático junto à comunidade, prioritariamente à comunidade externa. (ANEXO I - RESOLUÇÃO nº 102/2009 - CEPE)

Segundo o relatório anual de atividades da Unioeste (2013), elaborado pela Próreitoria de Planejamento - Proplan, a universidade possui atualmente três modalidades de fomento de bolsas de extensão: 1) Programa Universidade Sem Fronteiras; 2) Programa Ações Afirmativas e; 3) Programa Institucional de Bolsas de Extensão. Essas bolsas totalizaram-se em 279, no ano de 2013, distribuídas respectivamente conforme as modalidades em 165, 69, 45. Fazendo uma breve comparação no mesmo ano (2013) foram distribuídas 719 bolsas de iniciação cientifica na área de pesquisa, demostrando que as atividades de extensão ainda estão num processo de afirmação dentro da comunidade acadêmica.

\subsection{ATIVIDADES EXTENSIONISTAS DO CURSO DE ADMINISTRAÇÃO, CAMPUS FRANCISCO BELTRÃO}

O Curso de Administração foi criado no campus Francisco Beltrão, no ano de 2003, sendo uma ampliação de 40 vagas do Curso de Administração campus Cascavel, sendo reconhecido pelo Decreto Estadual no. 313 de 15/03/2007. No principio possuía ênfase em empreendedorismo, sendo após o ano de 2005, extinta a ênfase conforme as diretrizes dos Cursos de Administração, estipulados pela CNE/CES No 4, de 13 de julho de 2005 - MEC. O Curso, em 2014, conta com 08 professores efetivos, sendo 01 doutor, 03 em doutoramento e 04 mestres, além de 04 professores contratados temporariamente. Ressalta-se que este efetivo foi sendo formando aos poucos e ainda é insuficiente conforme o Projeto Pedagógico do Curso. Isso ocasionou um atraso nas atividades de pesquisa e extensão, sendo colocadas como prioridade as atividades de ensino.

Em 2014 encontram-se em atividade 3 (três) projetos de extensão de responsabilidade do Curso de Administração, sendo: a) Gestão estratégica para o primeiro emprego; b) Bom negócio Paraná e; c) Apoio ao processo de fortalecimento da gestão social, através da comercialização dos produtos da agricultura familiar. As atividades extensionistas são coordenadas e desenvolvidas por docentes, com a participação de egressos e acadêmicos em formação na administração e outros cursos das ciências sociais aplicadas. 


\subsubsection{PROJETO GESTÃO ESTRATÉGICA PARA O PRIMEIRO EMPREGO EM} FRANCISCO BELTRÃO- PR

Criado em 22/06/2009, esse projeto é resultante de outra atividade extensionista elaborado por um grupo de professores do colegiado do Curso de Administração que teve vigência no período de 15/05/2008 a 15/05/2009, cujo objetivo era proporcionar apoio pedagógico no desenvolvimento das atividades de ensino das ciências administrativas, focando conteúdos curriculares da área de marketing no curso técnico em Administração do Colégio Estadual Mario de Andrade no município de Francisco Beltrão. Após contatos com a comunidade local, o projeto foi reformulado, funcionando através da oferta de módulos semanais que abordam conteúdos específicos (formação técnica) e gerais (habilidades comportamentais), tais como: (i) noções de oratória; (ii) informática instrumental; (iii) elaboração de currículos e entrevista de seleção; (iv) empreendedorismo; (v) marketing pessoal; (vi) processo administrativo; (vii) noções de operações financeiras e de custos; (viii) responsabilidade socioambiental; (ix) relacionamento interpessoal e teste vocacional; dentre outros, através de pesquisas individuais, visitas a empresas e palestras realizadas por colaboradores internos (docentes e discentes da UNIOESTE), colaboradores externos e organizações parceiras locais do projeto (Prefeitura Municipal de Francisco Beltrão e Agência do Trabalhador). Ressalta-se que o projeto é operacionalizado de forma semestral, tendo no primeiro semestre de 2014 em funcionamento a $9^{\mathrm{a}}$ turma.

Possui como objetivo geral o desenvolvimento de ações que proporcionem o aumento da empregabilidade aos ingressantes ao mercado de trabalho no município de Francisco Beltrão/PR. É complementado pelos seguintes objetivos específicos: a) oportunizar a população a ingressar no mercado de trabalho; b) propiciar a qualificação técnica e comportamental do jovem para o mercado de trabalho; c) integrar o jovem às entidades de classe e parceiros do projeto. O publico assistido é formado por alunos do ensino fundamental e médio, preferencialmente da rede pública de ensino, com idade variando de 16 a 21 anos.

A execução das ações propostas é feita por docentes e egressos do Curso de Administração, também colaboram em algumas atividades específicas (em áreas como informática e comportamento profissional) servidores técnico administrativos da universidade e profissionais da agência do trabalhador. Um acadêmico em graduação atua como bolsista realizando atividades de secretaria e organização dos recursos e estrutura necessária às atividades do projeto. 
Na opinião da coordenação do projeto “[...] a atividade de extensão anda ao lado do ensino, uma vez que nas oficinas são abordados conteúdos específicos de administração e de formação geral habilidades humanas". O entrevistado considera que há relação direta das atividades do projeto com ensino e pesquisa. A pesquisa ocorre em fase anterior às oficinas do projeto "[...] buscando uma melhor forma de intervenção na realidade posta". Além disso, os resultados obtidos pelo projeto têm sido publicados em eventos de pesquisa e extensão, principalmente no SEU (Seminário de Extensão Universitária) realizado todos os anos em um dos campi da Unioeste, previamente escolhido.

4.1.2 PROJETO APOIO AO PROCESSO DE FORTALECIMENTO DA GESTÃO SOCIAL, ATRAVÉS DA COMERCIALIZAÇÃO DOS PRODUTOS DA AGRICULTURA FAMILIAR

Esta atividade foi aprovada com apoio de órgão de fomento externo à Unioeste, SETI/UGF fazendo parte do Programa Universidade sem Fronteira. As políticas públicas como Programa de Aquisição de Alimentos (PAA) e Programa Nacional de Alimentação Escolar (PNAE), criadas pelo governo federal, têm como objetivo garantir o acesso a alimentos em quantidade e regularidade necessárias às populações em situação de insegurança alimentar e nutricional. Especificamente, no caso do PNAE os recursos financeiros federais são repassados para Estados, Municípios e Distrito Federal, os quais devem utilizar 30\% dos recursos à aquisição da alimentação escolar com produtos oriundos da agricultura familiar. Para melhor atender essa demanda é necessário que os agricultores familiares estejam organizados e articulados. No entanto, muitas cooperativas de comercialização da agricultura familiar ainda não estão organizadas e estruturadas para desempenhar o papel de articuladora entre o produtor e os municípios compradores.

Este projeto que faz parte do Programa de Extensão Universidade sem Fronteira, subprograma Agricultura Familiar e Agroecologia, tem como objetivo organizar e qualificar estratégias que potencializem a rede de comercialização de alimentos, produtos e serviços da agricultura familiar e visa principalmente viabilizar o acesso às políticas públicas, a tecnologias de produção e comercialização, mediante organização da gestão social das cooperativas de comercialização, a fim de buscar competitividade para os produtos oriundos da agricultura familiar. O projeto é uma parceria entre União das Cooperativas da Agricultura Familiar - Unicafes e Unioeste, campus Francisco Beltrão. O público assistido são os cooperados integrantes de 11 (onze) cooperativas da agricultura familiar. 
O projeto é coordenado por 2 docentes (um do curso de Administração e outro do curso de Economia Doméstica) responsáveis pela orientação e acompanhamento das atividades de extensão e de pesquisas realizadas pelas bolsistas durante o desenvolvimento do projeto. Com duração prevista de 1 ano (maio/2013 à abril/2014) o projeto encontra-se em fase de relatório final das atividades realizadas. Fizeram parte da equipe, acadêmicos graduados e em fase de graduação dos cursos de Direito, Economia Doméstica, Ciências Econômicas e Administração.

Entre as atribuições dos acadêmicos envolvidos no projeto estão: (i) elaboração do diagnóstico das cooperativas de comercialização da agricultura familiar; (ii) participação de reuniões para discussão de prioridades e construção de plano de trabalho participativo com direção das cooperativas e Unicafes; (iii) verificação de documentos das cooperativas; (iv) assessoria na elaboração de projetos para fornecimento de alimentos através do PNAE e PAA; (v) pesquisa de mercado e elaboração de plano de marketing; (vi) relatórios, orientação técnica, pesquisa de campo e outros; (vii) adequações no fluxo de produção, transporte e comercialização de produtos. Também estão previstos a elaboração de trabalhos científicos e a socialização dos mesmos em cursos e eventos.

Ao ser entrevistada, a coordenadora desse projeto reforça que "[...] uma das diretrizes da extensão universitária, de acordo com a politica nacional de extensão é a "indissosiabilidade entre ensino-pesquisa e extensão". Acredita que tal relação se concretiza, no caso deste projeto, “[...] na execução de um projeto envolvendo professores e acadêmicos, há inicialmente ensino porque é preciso rever conteúdos aprendidos em sala e capacitar a equipe para a atividade especifica”. Durante o período do projeto, os alunos fazem pesquisa bibliográfica e de campo, analisam documentos, aplicam o conhecimento e ao mesmo tempo adquirem novos conhecimentos advindos do campo". Ressalta ainda que “[...] na extensão há ensino porque há troca de saberes entre a universidade e a sociedade e também há produção de pesquisa com publicações, mesmo porque a extensão também usa passos da pesquisa (problema, objetivos, justificativa, métodos, analise e resultados) incluindo a aplicação pratica no campo de atuação.

\subsubsection{PROJETO “BOM NEGÓCIO PARANÁ”}

Em 2012 a SETI/UGF lançou um edital específico com fomento da Universidade Sem Fronteira, para a implantação do programa estadual "Bom Negócio Paraná” que foi 
compulsoriamente alocado nas IES estaduais paranaenses. O projeto pretendia consolidar uma estratégia de transferência de conhecimentos teóricos sobre as práticas de gestão, envolvendo as principais áreas das ciências administrativas, como a finalidade de capacitar micro, pequeno, médio empresários e, informais empreendedores. Seguindo o modelo de tríplice hélice (atores do desenvolvimento) assim apresentado: $1^{\circ}$ ) vértice representado pelo poder público, constituído pelas prefeituras municipais dos municípios do Sudoeste do Paraná e a Associação dos Municípios do Sudoeste do Paraná, denominada pela sigla AMSOP (entidade de caráter civil), com a função de levantamento e captação do público ao qual se destina o projeto, além de proporcionar infraestrutura para algumas etapas do projeto; $2^{\circ}$ ) vértice representado pela instituição pública de ensino superior Unioeste, cuja finalidade é gerar e transmitir conhecimentos, utilizando-se do princípio da indissociabilidade entre ensino, pesquisa e extensão; $3^{\circ}$ ) vértice que é formado pela sociedade, representado nesse projeto pelos empresários de micro, pequenos e médios negócios, como também de empreendedores cuja a situação esteja ainda na informalidade.

Seu objetivo geral esta pautado no ensino, capacitação e orientação de empreendedores micro, pequeno, médio porte e informais da Região Sudoeste do Paraná, para melhor gerenciamento de seus negócios, contribuindo assim com o desenvolvimento local e regional. Aderidos a isso, estão os objetivos específicos que são: (i) promoção a transferência de conhecimentos, através de cursos de capacitação envolvendo as principais áreas da gestão de empresas; (i) oportunizar aos acadêmicos recém-formados e em formação, participantes do projeto, uma realidade dos conhecimentos teóricos aprendidos, capacitando-os para o desempenho profissional de sua formação; (ii) envolver a participação de docentes e discentes, através de projetos de extensão, com a finalidade de por em prática conhecimentos aprendidos no curso, bem como, possibilitar cenários de pesquisas de áreas específicas nas ciências administrativas e ciências econômicas.

O publico atendido é formado pelos empresários de micro, pequeno, médio porte e também, empreendedores informais, residentes na Região Sudoeste do Paraná, que é composto por 42 municípios. Para a operacionalização do projeto foi criado o núcleo Francisco Beltrão/Palmas, com a finalidade de coordenar as atividades, sendo composta por dois docentes (dos cursos de Administração e Ciências Econômicas) e originalmente por três alunos egressos desses dois cursos e dois alunos graduandos. Ressalta-se que o projeto está sendo renovado anualmente e a equipe de alunos egressos aumentou para seis componentes. 
Desde seu inicio até o presente momento foram abertas 28 turmas, capacitando 894 pessoas em 11 municípios integrantes da região de responsabilidade do núcleo Francisco Beltrão/Palmas.

Conforme o coordenador do projeto, “[...] o que chama mais atenção deste projeto é a oportunidade concedida aos recém-formados que podem desenvolver habilidades na prática, compensando dessa maneira o que o curso não ofereceu durante sua graduação”. O entrevistado ainda complementa afirmando que “[...] é uma pena que no campus não funcione uma empresa júnior ou tenha um projeto de extensão voluntário, no qual os graduandos poderiam antecipar conhecimentos práticos da realidade empresarial”. Para o inquerido a extensão não pode ser caracterizada como uma atividade complementar, "[...] e sim uma atividade curricular de extrema importância principalmente para os cursos de bacharelados em ciências sociais aplicadas, que possuem dificuldades de unir os conhecimentos teóricos com ações práticas em seus projetos pedagógicos”.

\section{ANÁLISE}

A investigação sobre extensão na Universidade Estadual do Oeste do Paraná e, mais especificamente, as atividades em andamento do curso de Administração do campus de Francisco Beltrão, subsidiam algumas constatações:

A universidade atribui importância à extensão visto que: possui na estrutura uma próreitoria responsável por tal atividade, considera as diretrizes e encontra-se alinhada à perspectiva de extensão exposta no plano nacional de extensão. Isto demonstra a existência de uma estrutura de pessoas e recursos voltados à prática da atividade extensionista na Unioeste;

No caso específico do curso de Administração de Francisco Beltrão verifica-se que os coordenadores entrevistados demonstram cada um à sua forma, que tem conhecimento das diretrizes da universidade no que se refere à extensão, estão empenhados na operacionalização dos respectivos projetos visto que as atividades demandam tempo e dedicação dos envolvidos;

Dos três projetos desenvolvidos no curso de Administração somente um, o de gestão estratégica para o primeiro emprego, foi criado e desenvolvido por docentes do curso, as atividades ocorrem através de parcerias entre instituições (públicas e privadas) e setores internos da universidade. Os demais projetos decorrem de atividades mais amplas envolvendo recursos públicos vindos de órgãos de fomento estadual. Neste projeto também é reduzida a 
atuação dos acadêmicos nas ações de formação dos iniciantes, limitada à atividade do bolsista que secretaria o projeto.

Foi constatado também que as atividades ocorrem de forma desarticulada com a graduação demonstrando a prática paralela, porém fragmentada, dificultando a articulação da tríade (ensino, pesquisa e extensão) interdisciplinar. Não há abertura para pesquisas de alunos não participante de projetos de extensão e tão pouco uma contribuição para o ensino, já que possuem exemplos da realidade administrativa. Sendo em poucos casos, com muita insistência a abertura de dados recolhidos no projeto servirem para trabalhos de conclusão de curso.

De forma geral, a análise das práticas desenvolvidas na instituição tendo por base os documentos consultados e a opinião dos coordenadores dos projetos aqui apresentados, permite inferir que, se por um lado, encontram-se alinhadas às diretrizes nacionais voltadas à extensão, de outro lado limitam-se à transmissão do conhecimento acadêmico. Tal prática tende a desconsiderar o saber implícito nas ações da comunidade receptora das atividades revelando a posição do extensionista como quem educa, ou, simplesmente transmite o conhecimento.

Entretanto há que se considerar que uma análise focada nos documentos e no depoimento dos coordenadores, pode representar uma limitação da pesquisa, pois, não revela percepções de outros envolvidos como acadêmicos, empresários ou iniciantes no mercado de trabalho que recebem a formação via extensão. Neste caso documentos e coordenadores expressam a visão institucional em relação à extensão limitada à condição de transmissão do conhecimento, apenas "de ida de quem pensa que sabe aos que acreditam que não sabem".

\section{CONSIDERAÇÕES FINAIS}

A realização do presente estudo possibilitou uma aproximação da temática da extensão universitária suscitando breves considerações. A busca por material bibliográfico revela a existência de reduzida produção científica tanto em termos conceituais quanto em termos descritivos de experiências extensionistas de instituições de ensino superior. A escassez se acentua na grande área das ciências sociais aplicadas, particularmente na administração, dessa forma a maior fonte de entendimento conceitual fica por conta de documentos oficiais como plano nacional de extensão e diretrizes curriculares. Tais documentos descrevem uma 
trajetória aperfeiçoada. A partir de 2000 a extensão passou a ser interpretada como elemento fundamental do tripé ensino, pesquisa e extensão sendo também elemento mediador da formação através da troca de conhecimento entre os envolvidos. Ainda assim, numa análise crítica, a extensão limita-se à transmissão de conhecimentos e técnicas e desconsidera a perspectiva de se tornar "troca de saberes".

No caso do curso de Administração confirma-se a visão da extensão como o primo pobre do tripé básico da formação sendo priorizados o ensino e a pesquisa. Entretanto, adaptada à área dos negócios a extensão se tornou alternativa de obtenção de recursos seja da iniciativa privada pela prestação de serviços, ou da esfera pública como incentivo à proliferação e/ou qualificação dos negócios. Também se se verificam o assistencialismo e a transmissão, o primeiro pelo uso de recursos públicos, e o segundo pela prática da extensão educativa difusora do conhecimento acadêmico.

Tratando-se da experiência da Unioeste o estudo demonstra um alinhamento da universidade com as diretrizes expostas nos documentos oficiais da extensão, isto se comprova na estrutura colocada à disposição da comunidade acadêmica para atividades e extensão. Constata-se uma diversidade de projetos e programas em andamento na universidade como um todo. Além disso, todas as ações são acompanhadas pelos setores pertencentes à pró-reitoria de extensão e passam por trâmites de avaliação da comunidade acadêmica após o encerramento das atividades. Por outro lado, diretrizes e ações da universidade são pautadas na perspectiva extensionista da transmissão de conhecimentos e técnicas acadêmicas.

Em relação aos projetos em andamento no curso de Administração do campus de Francisco Beltrão a pesquisa revela o envolvimento de docentes e acadêmicos nas atividades concretizando a função da extensão como elemento também formador do profissional. $\mathrm{Na}$ mesma direção a entrevista com os coordenadores dos projetos manifesta o conhecimento dos mesmos, mesmo que em maior ou menor intensidade, das diretrizes mais amplas e da articulação da extensão também com formadora. Neste caso também se confirma a prática da extensão que leva à comunidade o saber produzido na academia.

\section{REFERÊNCIAS}

BERTERO, C. O. Ensino e Pesquisa em Administração. São Paulo: Thomson Learning, 2006. 
BRASIL. Decreto Lei no 19.851 de 11/04/1931. Disponivel em $<$ http://www2.camara.leg.br/legin/fed/decret/1930-1939/decreto-19851-11-abril-1931505837-publicacaooriginal-1-pe.html>. Acesso em 12/dez/2014.

CARBONARI, M. E.; PEREIRA, A. C. Extensão Universitária - do assistencialismo à sustentabilidade. In: Revista de Educação Anhanguera, 2007.

CEPE - Conselho de Ensino, Pesquisa e Extensão. Resolução 193/2002, de 16/12/2002. Aprova o Plano Institucional de Extensão da Unioeste. Dispnível em $<$ http://www.unioeste.br/extensao/download/resolucoes/REScepe193.pdf $>$. Acesso em 26/abr/2014.

. Resolução no 199/2012, de 29/11/2012. Aprova o Projeto Pedagógico do curso de Administração, do campus de Francisco Beltrão. Disponível em $<$ http://www.unioeste.br/servicos/arqvirtual/arquivos/1992012-Cepe.pdf $>$. Acesso em 05/mai/2014.

. Resolução no 102/2009, de 14/05/2009. Aprova o Regulamento do Programa de Bolsas de Extensão da Unioeste. Disponível em $<$ http://www.unioeste.br/extensao/download/resolucoes/resolucao_102.pdf $>$. Acesso em 05/mai/2014.

. Resolução no 318/2005, de 20/10/2005. Aprova Regulamento do Programa de Bolsas de Extensão da Unioeste/PROEX. Disponível em $<\mathrm{http}$ ://www.unioeste.br/servicos/arqvirtual/arquivos/3182005-CEPE.pdf $>$. Acesso em 05/mai/2014.

CORRÊA, E. J. Extensão universitária, política institucional e inclusão social. In: Revista Brasileira de Extensão Universitária. v.1 n.1, pag 12-15, jul/dez/2003.

CRUZ et al. Extensão Universitária e Responsabilidade social: 20 anos de experiência de uma instituição de ensino superior. In: XXXIV ENANPAD Rio de Janeiro, setembro/2010.

DIAS, A. Discutindo caminhos para a indissociabilidade entre ensino, pesquisa e extensão. In: Revista Brasileira de Docência, Ensino e Pesquisa em Educação Física. v.1 n.1 pag 37-52, Agosto/2009.

FORPROEX. Fórum Pró reitores de Extensão universitária. Disponível em <pt.scribd.com/doc/217762939/02-Politica-Nacional-Extensao>. Acesso em 10/mai/2014.

FREIRE, P. Extensão ou comunicação. Rio de Janeiro: Paz e Terra, 1977.

LAKATOS, E. M.; MARCONI, M. de A. Fundamentos da Metodologia Científica. 7 ed. São Paulo: Atlas, 2010.

MARTINS, L. M. Ensino-Pesquisa-Extensão como fundamento metodológico na construção do conhecimento na universidade. In: Oficina de estudos pedagógicos. São Paulo, 2007b. Disponível em $<$ http://www.umcpos.com.br/centraldoaluno/arquivos/16_09_2011_134/Ensino_pesquisa_ext 
ensao_como_fundamento_metodologico_da_construcao_do_conhecimento_na_universidade. pdf $>$ Acesso em 08/abr/2014.

MINISTÉRIO DA EDUCAÇÃO - MEC. Resolução nº 4, de 13/07/2005, Institui as Diretrizes Curriculares Nacionais do Curso de Graduação em Administração, bacharelado, e dá outras providências. Disponível em: < http://portal.mec.gov.br/cne/arquivos/pdf/rces004_05.pdf> . Acesso em 12/mai/2014

PROPLAN - Pró-reitoria de Planejamento. Relatório anual de atividades - exercício 2013. Disponível em: $<$ http://cac-

php.unioeste.br/proplan/docs/2013/Relatorio_UNIOESTE_2013_pdf.pdf $>$. Acesso em 20/mai/2014.

. Boletim de dados 2013. Disponível

em: $<$ http://www.unioeste.br/proplan/boletimdedados2013> . Acesso em 20/mai/2014.

ROCHA, R. M. G. A Construção do Conceito de Extensão universitária na América Latina. In. FARIA, Doris Santos de (org). Construção Conceitual da Extensão na América Latina. Brasília. Editora UNB. 2001.

SERRANO, R. M. S. M. Conceitos de extensão universitária: um diálogo com Paulo Freire. Grupo de pesquisa em Extensão Popular Atividades: Artigos para discussão 2008. Disponível em <http://www.prac.ufpb.br/copac/extelar/atividades/discussao/artigos/concei tos_de_extensao_universitaria.pdf $>$ Acesso em 10/mai/2014

SOUSA SILVA, A. A. O Programa UFBA em campo ACC: sua contribuição na formação do estudante. In: Revista Faced n.13 p.83-102. Salvador jan/jun/2008.

VARGAS, G.; FELIX, G.; MATOS, M. Análise da evolução da extensão da Universidade Federal de Santa Catarina no período de 1997-2003. In: Colóquio Internacional sobre Gestão Universitária na América do Sul. Florianópolis 8 a 10/12 de 2004. 